\title{
Protective Effectiveness of Superhydrophobic Self-Organizing Surface Films in the Presence of Stimulants of Atmospheric Corrosion of Steel
}

\author{
V.I. Vigdorovich ${ }^{1,3}$, L.E. Tsygankova ${ }^{2}$, N.V. Shel ${ }^{3}$, E.Yu. Shel ${ }^{3}$ \\ ${ }^{1}$ All-Russian Scientific Research Institute for the Use of Machinery and Petroleum Products in Agriculture, \\ 28, Novo-Rubezhny per., Tambov, 392000, Russia; \\ ${ }^{2}$ G.R. Derzhavin Tambov State University, 33, Internatsionalnaya St., Tambov, 392000, Russia; \\ ${ }^{3}$ Tambov State Technical University, 106, Sovetskaya St., Tambov, 392000, Russia \\ * Corresponding author: Tel.: +7 47527236 55.E-mail: vits21@mail.ru
}

\begin{abstract}
The paper summarizes the literature data of mainly foreign researchers and the authors' own results concerning the corrosive and electrochemical behavior of metallic materials with a superhydrophobic surface in solutions of electrolytes. Much attention is paid to the methods of superhydrophobic layer formation, the mechanism and kinetics of electrode processes, metal corrosion and icing. Separate sections are devoted to inhibition of corrosion and icing, interpretation of modern approaches to their explanation.
\end{abstract}

\section{Keywords}

Steel; copper; binary alloys; superhydrophobization; electrode reactions; icing; mechanism; kinetics; inhibition.

(C) V.I. Vigdorovich, L.E. Tsygankova, N.V. Shel, E.Yu. Shel, 2018

\section{Introduction}

Over the past decades, systematic studies of superhydrophobization of metal surfaces to increase their corrosion resistance, anti-icing ability and obstruction of pollution have been conducted. The action of coatings that increase the contact angle of wetting with water to $\theta \geq 150^{\circ}$ and reduce the angle of its rolling down to $\sim 10^{\circ}$ is considered. In publications [1-42], which represent only a small amount of their real number, much attention is paid to the application of protective films of superhydrophobizers, which make it possible to increase the contact angle to 165 $171^{\circ}$ [18]. The protective effect of such films under conditions of electrochemical corrosion is due to the following. These processes and the rate of atmospheric and other types of corrosion of metal structural materials are largely determined by stimulation of partial electrode reactions by water molecules.

\section{The nature of corrosion inhibition}

The process of corrosion stimulation by water molecules is primarily due to their direct participation in one or more stages of partial electrode reactions.
Therefore, the meaning of this method of protection is as follows: if there is no participant in the corrosion process, there is no corrosion destruction itself. This was discussed in greater detail in [43].

\section{The nature of icing braking}

Another important property of superhydrophobic surfaces [SHFS] is that they prevent sticking of wet snow, ice and frost, leading to a sharp decrease in ice adhesion and preventing icing of working surfaces [7-11]. Since this issue has not been sufficiently studied in domestic literature, we consider it in more detail. Superhydrophobic surfaces with high contact angle are characterized by low contact-angle hysteresis. In [12] the studies showed the existence of a quantitative relationship of value $\theta$ with the adhesion of ice. Superhydrophobicity prevents or reduces ice adhesion for the following reasons [13]:

1. The insulating effect of the nanostructured rough surface complicates heat transfer. The microstructure on the superhydrophobic surface acts as an insulating layer on the interface.

2. The contact area between the surface and a water droplet is significantly reduced at SHFS. 
This causes an increase in the activation energy of nucleation and growth of ice crystals.

3. Water droplets on the SHFS are characterized by increased mobility, which makes it easier to combine under shaking and impact, or bounce off the surface. This significantly reduces the contact time of the droplet with the surface, causing a ricochet phenomenon and contributing to the removal of water. In such conditions, icing is difficult or not observed at all $[14,15]$. This is important for functioning of radars [16] and improves the efficiency of insulators [17]. The authors [18] note the expediency of using coatings that prevent icing, for which it is recommended to use self-organizing monolayers with $-\mathrm{CH}_{3}-$ и $-\mathrm{CF}_{3}-$ groups oriented to the ice surface as one of hydrophobization conditions for hydrophilic surfaces $[41,42]$.

In addition, reverse cyclical changing wettability from $\theta>150^{\circ}$ to $\theta<5^{\circ}$ and back is necessary for effective self-cleaning of surfaces [41, 42, 44, 45], with controlled drug delivery. These processes are relatively easy for control, as UV radiation and dark treatment contributes to the hydrophilization, and heat treatment (annealing) - hydrophobization [46] of the surface.

In the case of a perfectly smooth surface, the contact angle $\theta$ is determined by the Young's equation [47]:

$$
\cos \theta=\left(\sigma_{\mathrm{a} / \mathrm{s}}-\sigma_{1 / \mathrm{s}}\right) / \sigma_{1 / \mathrm{s}},
$$

where the lower index of the letters "a", "l" and "s" characterize, air, liquid and solid phases, respectively; $\sigma_{i}$ is the surface tension at the boundary of the corresponding phases. It is easy to see that at the possible changes of the $\sigma_{\mathrm{a} / \mathrm{s}}$ value $\theta$ may vary within wide limits: from complete wetting $(\theta=0)$ to superhydrophobic state of the surface. The value $\theta<90^{\circ}$ was observed at $\sigma_{\mathrm{a} / \mathrm{s}}>\sigma_{1 / \mathrm{s}}$ or $\left(\sigma_{\mathrm{a} / \mathrm{s}}-\sigma_{1 / \mathrm{s}}\right)>0$.
If for the water $\theta>90^{\circ}(\cos \theta<0)$, and the solid is well wetted with hydrocarbon, the surface is the hydro- or superhydrophobic or oleophilic. Similar examples are given in Table 1. It is noteworthy that the growth in the value of the contact angle is antisymbatic to the reduction of surface energy [1]. However, wetting of perfectly smooth surfaces is extremely rare. According to [1], the effect of chemical heterogeneity can be taken into account by means of the Cassie equation:

$$
\cos \theta=\sum f_{i} \cos \theta_{i, 0},
$$

where $f_{i}$ is the share of the smooth surfaces of the $i$-th type characterized by the contact angle $\theta_{i, 0}$.

On substrates with deep pores, two types of liquid droplet equilibrium modes homogeneous and heterogeneous types of wetting are possible. In the first case, the pores of the substrate are completely filled with the liquid phase (Fig. 1a), in the second one they are not filled at all (Fig. 1b).

There can be a set of intermediate variants between them [48], when on some parts of the surface the case shown in Fig. 1a is realized, and on some parts - the case shown in Fig.1b is realized. This possibility is confirmed by the data [49]. The data on the impact of the nature and structure of the substrate on the contact angle were generalized in [1]. We note some features of such impact which have been observed recently.

A number of fundamentally important results were generalized in $[50,51]$, where the authors electrochemically applied the $\mathrm{Ni}-\mathrm{Co}$ alloy films to the copper surface. The obtained results made it possible to connect the structure and chemical composition of the formed film with the contact angle value. At the same time, according to the authors, they identified the key factors affecting the level of wetting.

Table 1

\begin{tabular}{|c|c|c|c|c|c|c|c|}
\hline \multirow{3}{*}{$\begin{array}{l}\text { The nature of the } \\
\text { liquid phase }\end{array}$} & \multirow{3}{*}{$\begin{array}{c}\text { Steel Ст3 } \\
\text { [51] }\end{array}$} & \multirow{3}{*}{ Copper [51] } & \multicolumn{4}{|c|}{ Nature of the solid phase } & \multirow{3}{*}{$\begin{array}{c}\mathrm{PFE} * * \\
{[52]}\end{array}$} \\
\hline & & & \multicolumn{4}{|c|}{ PMFS* with number of $\mathrm{CF}_{2}$-groups [52] } & \\
\hline & & & 3 & 5 & 7 & 9 & \\
\hline Water & 77.0 & 82.0 & 105.0 & 102.4 & 104.7 & 109.3 & 122 \\
\hline $\begin{array}{r}0.5 \mathrm{M} \mathrm{NaCl} \\
\text { (in water) }\end{array}$ & 77.0 & 81.0 & - & - & - & - & - \\
\hline $\mathrm{H}-\mathrm{C}_{7} \mathrm{H}_{16}$ & 0 & 0 & - & - & - & - & - \\
\hline $\mathrm{H}-\mathrm{C}_{10} \mathrm{H}_{20}$ & 0 & 0 & - & - & - & - & - \\
\hline
\end{tabular}

\section{Values of contact angles $\left(^{\circ}\right)$ on different surfaces [1]}




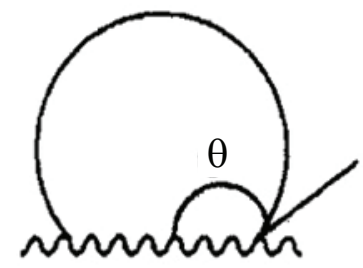

a)

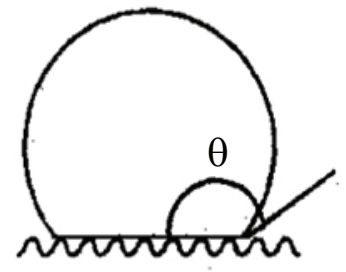

b)
Fig. 1. Droplet on the substrate:

$a$-homogeneous wetting mode on a rough substrate;

$b$-heterogeneous mode of wetting on a rough substrate

They are:

- the level of roughness (r) of the surface, with high $r$ being one of the main factors of increasing the contact angle and reducing the rolling angle;

- another key factor is the morphology of the surface, as the air in the composition of the surface structure plays an important role in obtaining the required values of the contact and rolling angles. The structure, which the authors [50] call as "flowerlike", either stimulates the accumulation of air, depending on the physical size of the roughness or prevents this. However, there is another key factor that manifests itself in the process of aging. It is the chemical composition of the surface. In the process of aging oxidation of the metal surface (Ni-Co alloys) occurs with the formation of surface oxides of $\mathrm{NiO}$ and CoO. In addition, there is adsorption of hydrocarbons, which is confirmed by the emergence of fragments with $\mathrm{C}-\mathrm{C}-, \mathrm{C}-\mathrm{H}, \mathrm{C}-\mathrm{O}-$ and $\mathrm{C}-\mathrm{O}-$ bonds. Both of the latter factors also contribute to a significant decrease in wettability by water with an increase in the contact angle to $158^{\circ}$ [50].

According to [50], a "micro-flower" structure can be observed on the surface. There are nanoangles with figures type of nanocone with a diameter of 100 $500 \mathrm{~nm}$ and lateral spirals on it. Experimentally, an increase in the size of such formations is often observed. Reduction in the crystallite size is possible due to the fact that the nucleation rate becomes greater than their growth rate. This leads to a finer surface structure.

The structure observed in [50] corresponds to the decrease in the value $\theta$. The subsequent increase in the duration of coating formation does not change $\theta$, which is explained by an increasing heterogeneity of the structure.

Schematically, the behavior of the water droplet on the surfaces of different structures is shown in Fig. 2 [50]. The largest contact area between the droplet and the surface is reached on a flat substrate (Fig. 2a) [50]. It decreases with the transition to the nanocone structure (Fig. 2c) [50], when a droplet can no longer be on the surface and penetrates into nanocones.

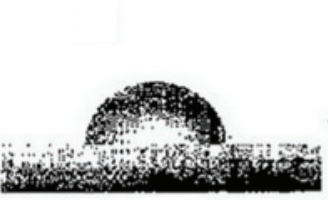

a)

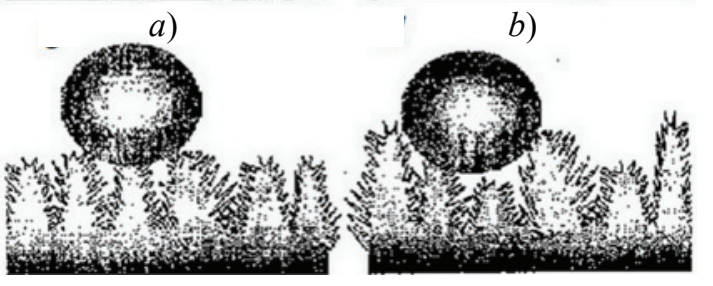

c)

d)

Fig. 2. Schematic representation of the wetting process for a flat $(a)$, nanoconic $(b)$, micro-flower homogeneous $(c)$ and micro-flower heterogeneous $(d)$ structures [50]

The picture observed at the cathodic formation of the Ni-Co layer at $i_{\mathrm{c}}=30-40 \mathrm{~mA} / \mathrm{cm}^{2}$ and the electrolysis time of more than $600 \mathrm{~s}$ is shown in Fig. $2 c$ [50]. This creates a fairly uniform structure that does not allow a droplet of water to be partially in the pockets, performing the function of the air traps, which leads to superhydrophobicity of the surface. The structure in Fig. $2 d$ [50] leads to a decrease in the value $\theta$.

The created surface film of $\mathrm{Ni}-\mathrm{Co}$ alloy is characterized by the rolling angle of more than $10^{\circ}$. The contact angle is probably close to $85^{\circ}$, as it was on the copper surface, but it depends on the roughness factor in accordance with the Venzel equation [53]:

$$
\cos \theta=r \cos \theta_{0},
$$

where $r$ is the coefficient of roughness equal to the ratio of the true surface area to the apparent one, $\theta$ and $\theta_{0}$ were found earlier.

The growth in the value $\theta$ due to sorption of hydrocarbons previously was interpreted in [50] in the cobalt-based coating.

\section{Description of the braking mechanism by superhydrophobic surfaces}

Chemical stability is an important factor in the use of superhydrophobic films [41], which meet technological and economic requirements. However, the protective efficiency of such films can be increased by the introduction of organic inhibitors [55-58]. In particular, fatty amines [41], i.e. a number of chemical reagents with the $-\mathrm{NH}_{2}$ group and a long hydrocarbon chain are quite effective [59]. In such a case, on the one hand, an amino group forming a complex with a metal such as copper [41] works due to donor-acceptor interaction. On the other hand, the long 
-C-C- chain determines the hydrophobic properties of the film. In [41], a one-stage electrochemical method for creating a laurylamine-based film was proposed.

As noted above, the surfaces with reversible wettability are of considerable interest, when the contact angle reversibly and cyclically changes from $150^{\circ}$ to $5^{\circ}$ and back [41]. This effect is used in selfcleaning of surfaces [41], various biomaterials [20, 21], sensory systems [43], and controlled delivery of drugs [41] to the organs of living organisms in their pathology. Take for instance $\mathrm{ZnO}$, which is a promising material for the creation of functional structures [42], for which the physical and chemical properties of zinc oxide, its structure and other characteristic parameters are essential. The directed controlled synthesis of materials based on ZnO-nanowires [27, 28], nanorods [29], and nanotubes [30] has been developed so far. The production of zinc oxide films with superhydrophobic properties was successfully achieved by numerous methods, including an electrochemical synthesis [31-33], vapor condensation [34, 35], thermal evaporation [36], self-organized growth [37], a hydrothermal method [38-40]. In particular, the possibility of wurzite production by electrodeposition from $\mathrm{Zn}\left(\mathrm{NO}_{3}\right)_{2}$ solution was shown for the first time. In [40], bundles of nanowires well-oriented on silicon were obtained with subsequent their modification by fluoroorganic compounds (a hydrothermal method). The magnitude of the contact angle $\theta$ was order of $165^{\circ}$. In [34] it was reported about reversible transition of hierarchical $\mathrm{ZnO}$ film from superhydrophobicity to superhydrophilicity (UV radiation, a dark method) and back by heat treatment $\left(\theta-164^{\circ}\right)$.

However, according to [42], most synthesis methods require complex operations and the use of specific organic compounds to achieve superhydrophobicity surface. Such systems are easily damaged and contaminated. One of the most costeffective, affordable and well-managed methods is the $\mathrm{ZnO}$ electrodeposition on a zinc substrate. In this case, the production of superhydrophobic coating is achieved by electroforming followed by annealing, but without chemical modification. In [42], the morphology of the film based on this oxide, the growth mechanism, stability and corrosion resistance, or rather the protective efficiency of the superhydrophobic surface based on $\mathrm{ZnO}$ were investigated.

In [42] electroforming of surface oxide $\mathrm{ZnO}$ was carried out in a three-electrode electrochemical cell with zinc foil as anode and platinum cathode. An electrolyte solution containing $0.1 \mathrm{mmol} / 1$ $\mathrm{Zn}\left(\mathrm{CH}_{3} \mathrm{COO}\right)_{2}$ and $0.3 \mathrm{~mol} / \mathrm{l} \mathrm{KCl}$. Electrodeposition was carried out at a constant potential equal to $1.0 \mathrm{~V}$
(NHE) for $900 \mathrm{~s}$. Then the resulting surface was washed with water and dried in air [42].

The values of the contact angles were:

1) untreated $\mathrm{Zn}-(62 \pm 2)^{\circ}$;

2) etched in $1,0 \mathrm{M} \mathrm{HCl}-(29 \pm 2)^{\circ}$;

3) electrodeposited at a potential of $1.25 \mathrm{~V}$ for $900 \mathrm{~s}-(40 \pm 2)^{\circ}$

4) annealed at $200{ }^{\circ} \mathrm{C}$ for 60 minutes $-(170 \pm 2)^{\circ}$.

The structure of the formed film depends significantly on the concentration of $\mathrm{Zn}\left(\mathrm{CH}_{3} \mathrm{COO}\right)_{2}$ in the ethanol solution [42]. The evaluations were carried out in the first 5-40 minutes from the beginning of electrolysis. The roughest structure was formed after annealing the system obtained by electrolysis of $\mathrm{ZnO}$ $(E \approx-1.0 \mathrm{~V}, \tau-900 \mathrm{~s})$ and its subsequent heat treatment under the above conditions.

The authors [42] proposed a stage mechanism of the electrolytic formation of $\mathrm{ZnO}$, when $\theta$ at the initial moment was about $(170 \pm 2)^{\circ}$. However, in time the contact angle was rapidly reduced and after 30 minutes (with UV radiation) it was close to $5^{\circ}$. The process cycling: annealing/UV radiation resulted in the constancy of the decay kinetics from $\theta_{\max }$ to $\theta_{\min }$ and a return to the original $\theta_{\max }$ (annealing).

The high inhibiting capacity of $\mathrm{CH}_{3}\left(\mathrm{CH}_{2}\right)_{11} \mathrm{NH}_{2}$ was previously noted. According to [41], during the electrolytic treatment of copper in the ethanol solution of laurylamine $\left(99.5 \% \mathrm{C}_{2} \mathrm{H}_{5} \mathrm{OH}\right)$, the actual atoms of $\mathrm{Cu}$, oxygen and nitrogen were observed on its surface. According to the authors, the first two elements belong to $\mathrm{CuO}$. The effective size of the particles of formed copper oxide and their shape depends on the duration $\left(\tau_{\mathrm{d}}\right)$ of the direct current flow, and increases with an increase in $\tau_{\mathrm{d}}$. According to the authors [41], there is a stage mechanism of formation of copper surface complexes.

The forming complexes concentrate on the interface of the L/S phases, forming a fairly dense structure. The value of the contact angle of the water drop in the initial period increases in time and in 60 minutes reaches $(155 \pm 2)^{\circ}$, and then remains almost unchanged.

The water contact angle as a function of the terminal voltage in the formation of the surface film takes the following values $(\theta=f(V))$ at the following values $V: 5 \mathrm{~V}-116.3^{\circ} ; 10 \mathrm{~V}-153.6^{\circ} ; 30 \mathrm{~V}-152.4^{\circ}$; $50 \mathrm{~V}-138.2^{\circ}$.

In accordance with the Cassi model [55], if the contact angle of water in air is $180^{\circ}$, the dependence $\Delta \theta_{r}=f($ surface state) has the form:

$$
\cos \theta_{r}=r S_{1} \cos \theta-S_{2},
$$



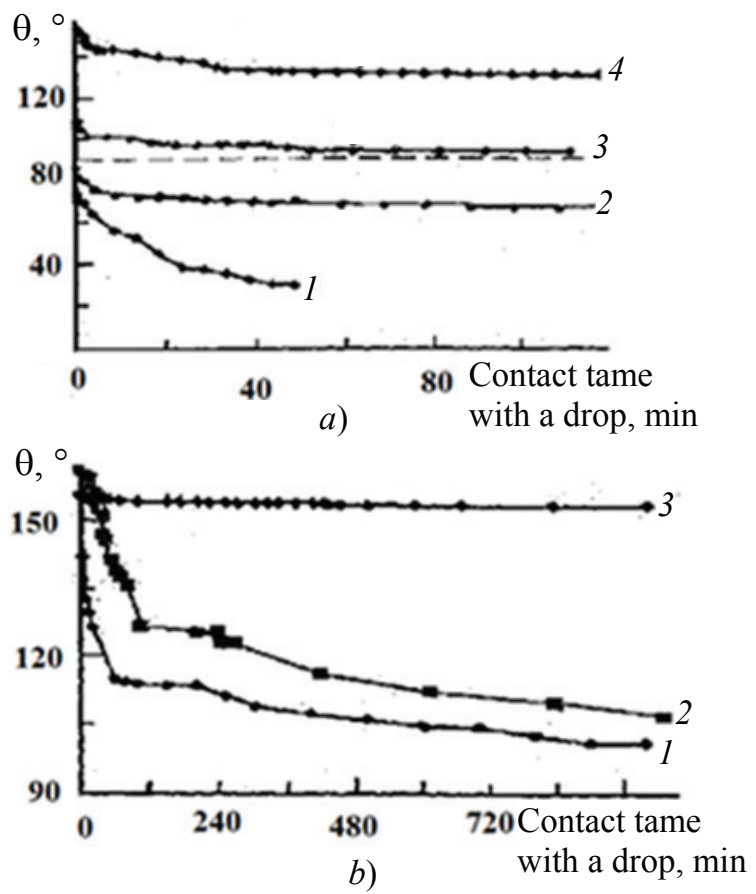

Fig. 3. Dynamics of change in the water droplet contact angle on composite superhydrophobic coatings formed on a magnetite sublayer obtained by St3 oxidation in ammonium nitrate solution [5]:

a: 1 - no coating; 2 - magnetite coating; 3 - magnetite coating with $\mathrm{MAF}_{i}$ hydrophobic coating; 4 - magnetite coating with textured superhydrophobic surface (Aerosil particles on $\mathrm{MAF}_{i}$ );

b: 1 - magnetite coating; 2 - magnetite coating obtained in $\mathrm{NH}_{4} \mathrm{NO}_{3}$ with IFKHANOX-8; 3 - magnetite coating obtained in $\mathrm{NH}_{4} \mathrm{NO}_{3}$ solution with IFKHANOX-9A

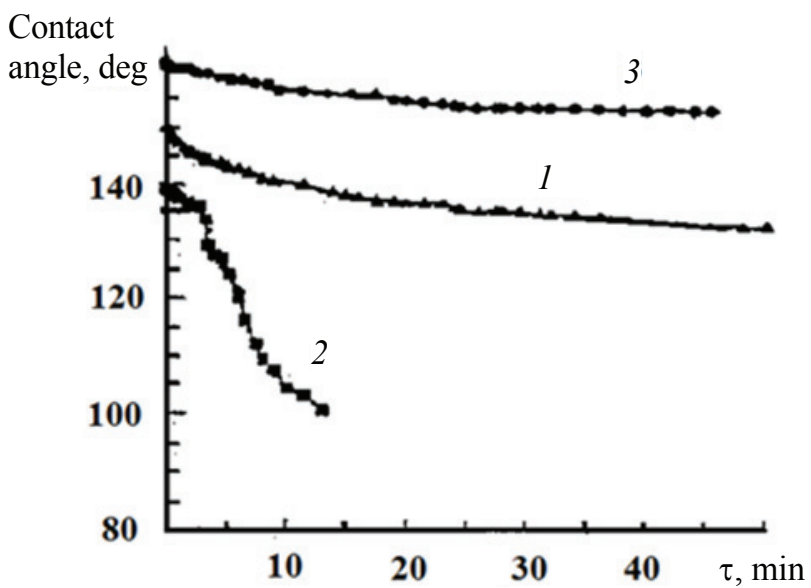

Fig. 4. Dynamics of change of the water droplet contact angle on St3 steel:

1 - with a standard oxophosphate coating treated with a hydrophobic agent; 2 - with an oxophosphate coating modified by cerium and treated with a hydrophobic agent; 3 - with a superhydrophobic coating formed on oxophosphate sublayer modified by cerium [5] where $S_{1}$ and $S_{2}$ are surfaces occupied by solid phase and air, $r$ is the roughness coefficient; $\theta_{r}$ and $\theta$ are the contact angles on a rough and smooth surface. Thus, $\theta_{r}$ increases with increasing area of the gas phase separating the solid surface and the liquid solution [42]. The decrease in $\theta_{r}$ as a function of time is due to the decrease in the air space, which is gradually displaced by the liquid phase.

Now, we consider the protective ability of superhydrophobic coatings as one of the most important factors of their practical use. In [5], the magnetite coating (MC) was formed on St3 steel by oxidation in a solution of ammonium nitrate without additives and with IFKHANOX-8.9A. Simultaneously, the effectiveness of oxyphosphate coating (OPC) was evaluated when MAF-99 $\left(\mathrm{HCF}_{2}\left(\mathrm{CF}_{2}\right)_{5} \mathrm{HCO}\left(\mathrm{CH}_{2}\right)_{3} \mathrm{Si}\left(\mathrm{OCH}_{3}\right)_{3}\right)$ or $\mathrm{MAF}-171$ $\left(\mathrm{HCF}_{2}\left(\mathrm{CF}_{2}\right)_{5} \mathrm{HCO}\left(\mathrm{CH}_{2}\right)_{3} \mathrm{Si}\left(\mathrm{NHCH}_{3}\right)_{3}\right)$ superhydrophobizers were applied to the magnetite or OPC. For the formation of surface films by means of $\mathrm{MAF}_{\mathrm{i}}$, their sorption application from $\mathrm{H}-\mathrm{C}_{10} \mathrm{H}_{22}$ was carried out. Then, dispersion of the Aerosil nanoparticles was additionally applied to the formed $\mathrm{MAF}_{i}$ film after its special treatment.

The details of the method were given in [5]. The corrosion tests were carried out in an atmosphere with $100 \%$ relative humidity or in a thermal chamber with temperature cycling in the range of $40-25{ }^{\circ} \mathrm{C}$. Taking into account the significant influence of the contact angle on the protective efficiency of hydrophobic and superhydrophobic films (application of Aerosil particles), the kinetics of the change in the value $\theta$ was evaluated (Fig. 3 and 4) [5].

The results of corrosion tests are summarized in Tables 2 and 3 [2].

The authors assume the following:

- treatment of conversion coatings (CCs) formed on low carbon steel with hydrophobizer on base of fluorooxysilane increases the water droplet wetting angle, but does not permit to protect the steel surely from atmospheric corrosion under conditions of $100 \%$ humidity;

- the use of superhydrophobizing treatment of CCs makes it possible to increase the edge angle to values above $160^{\circ}$, which has a positive effect on the improvement of the $\mathrm{CCs}$ protective ability in accelerated corrosion tests at $100 \%$ relative humidity;

- the maximum resistance in continuous contact with water is typical for superhydrophobic surfaces formed on magnetite coatings obtained by oxidation in ammonium nitrate solution without modifying additives. In conditions of testing in the thermal 
chamber the best results were obtained for superhydrophobic surfaces on steel with magnetite coating formed in the IFKHANOX-9A solution. Such a composite coating increases the duration of steel protection from 1 to 50 days.

However, in most cases, when assessing the protective ability of hydrophobic and superhydrophobic films, many authors tend to neglect the data of direct corrosion tests. The study in [54] is an important exception.

The assessment is usually carried out by measuring polarization curves and determining the corrosion rate by extrapolating their Tafel regions for corrosion potential $[53,56]$. The method of impedance spectroscopy is used and the calculation of $i_{\text {cor }}$ is carried out by means of the polarization resistance $R_{\mathrm{p}}$ in accordance with the Stern-Geary equation:

$$
i_{\text {cor }}=\frac{2.3 R_{\mathrm{p}}\left(B_{\mathrm{a}}+B_{\mathrm{c}}\right)}{B_{\mathrm{a}} B_{\mathrm{c}}},
$$

where $B_{\mathrm{a}}$ and $B_{\mathrm{c}}$ are the tafel slopes of the anodic and cathodic polarization curves branches.

In [50] the SHFS protective efficacy on the basis of methoxy - $\{3-[(2,2,3,3,4,4,5,5,6,6,7,7,8,8,8$ pentadecafluorooctanoic)-oxy] propyl $\}$-silane deposited from $\mathrm{H}-\mathrm{C}_{10} \mathrm{H}_{22}$ (1st series of samples) on the textured surface of steel $(3 \% \mathrm{NaCl})$ was examined, the details of the methodology are in [43]. The dependence of its protective action $\gamma$ as a function of time is shown in Fig. 5. The results were obtained on the samples of the 1 st and 2 nd series. In the case of coatings of the 2 nd series, an additional aerosol Aerosil was applied.

It is easy to see that the stationary level of protection was achieved after 72 hours of treatment and lasted for at least $168 \mathrm{~h}$. In this case $\gamma=K_{0} / K_{\text {coat }}$, where $K_{0}$ and $K_{\text {coat }}$ are the corrosion rate of unprotected steel and the corrosion rate of the steel with superhydrophobic coating, respectively, and it has a value of $(23 \pm 3)$.

As follows from the data of polarization measurements (Fig. 6), the application of SHFS on zinc also significantly inhibits the corrosion rate in $3.5 \%$ $\mathrm{NaCl}$ solution [52].

In this case, carbon fibers obtained by the destruction of acetylene were superhydrophobizer. It is important that the preliminary deaeration of the working solution dramatically increases the corrosion rate by stimulating the cathode and anode processes. This fully confirms the interpretation presented in $[53,56]$. The fact is that in the process of deaeration the air film is removed and the contact of the electrolyte solution with the metal surface is facilitated.
A similar situation, naturally, affects the corrosion rate of zinc, including that estimated from polarization measurements. Thus, the corrosion current density of unprotected zinc in a $3.5 \%$ aerated solution under the conditions studied in [42] (room temperature) is of the

Table 2

Results of corrosion tests of St3 steel with magnetite coating and oxyphosphate coating at $100 \%$ relative humidity in the thermal chamber

\begin{tabular}{lcc}
\hline \multicolumn{1}{c}{ Coating } & Hydrophobizer & $\begin{array}{c}\text { Time until } \\
\text { the corrosion } \\
\text { distortion, days }\end{array}$ \\
\hline Magnetite & MAF-99 & 19 \\
coating & MAF-171 & 23 \\
Oxyphosphate & MAF-771 with Aerosil & 45 \\
coating & - & 30 \\
\hline
\end{tabular}

Table 3

Results of corrosion tests of St3 steel with magnetite coating formed in oxidized solutions

with the subsequent application of superhydrophobizer film or IFKHANOX -8, 9A passivation [57]

\begin{tabular}{llc}
\hline \multicolumn{1}{c}{$\begin{array}{c}\text { Oxidizing } \\
\text { solution }\end{array}$} & \multicolumn{1}{c}{ Aftertreatment } & $\begin{array}{c}\text { Time until } \\
\text { the occurrence } \\
\text { of corrosion } \\
\text { distortion, days }\end{array}$ \\
\hline $\mathrm{NH}_{4} \mathrm{NO}_{3}(25 \mathrm{~g} / \mathrm{l})$ & None & $<1$ \\
IFKHANOX-8 & Passivation & 23 \\
& Superhydrophobixation & 30 \\
IFKHANOX-9A & Passivation & 25 \\
& Superhydrophobization & 50 \\
\hline
\end{tabular}

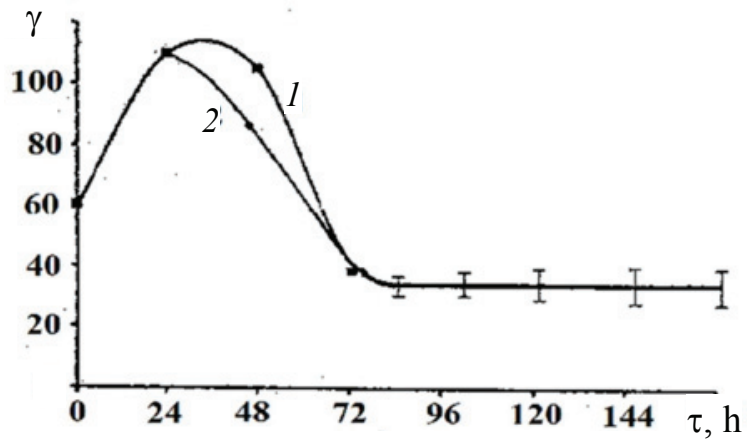

Fig. 5. The dependence of the protective effect of hydrophobized coating on the duration of steel exposition in $0.5 \mathrm{M} \mathrm{NaCl}$ solution:

1 - samples of the 1 st series; 2 - samples of the 2 nd series 


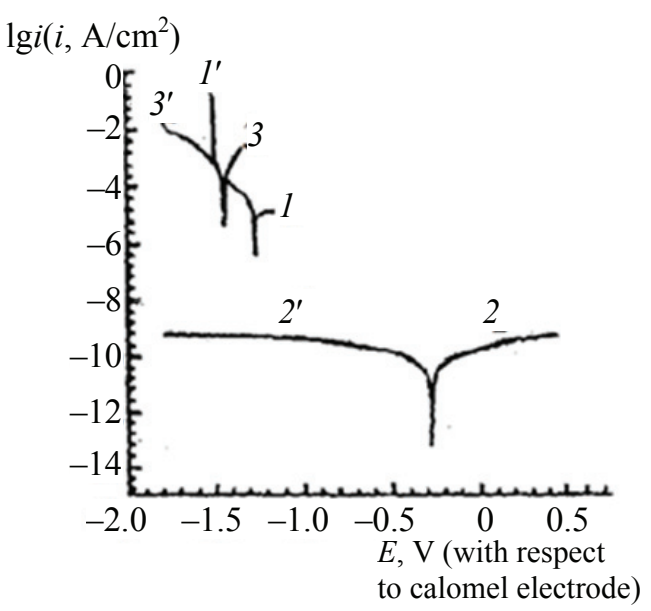

Fig. 6. Polarization curves in $3.5 \% \mathrm{NaCl}$ solution: 1 and $l^{\prime}$ - pure zinc before aeration;

2 and $2^{\prime}-$ zinc with a superhydrophobized layer before aeration; 3 and $3^{\prime}-$ zinc with a superhydrophobized layer after deaeration [52]

order of $10^{-1} \mathrm{~A} / \mathrm{m}^{2}$. But in the same deaerated medium, zinc with a superhydrophobic surface corrodes at a rate of $10^{-2} \mathrm{~A} / \mathrm{m}^{2}$, i.e. an order of magnitude smaller, and in an aerated solution, when the interlayer of air is relatively stable, with $i_{\text {cor }}$ of the order of $10^{-5} \mathrm{~A} / \mathrm{m}^{2}$, i.e. a thousand times smaller.

Accordingly, the charge transfer resistance obtained in [42] from the impedance measurements is $272 \mathrm{Ohm} \cdot \mathrm{cm}^{2}, \quad \sim 5,1 \cdot 10^{4} \mathrm{Ohm} \cdot \mathrm{cm}^{2}$ and $\sim 8,2 \times$ $\times 10^{8} \mathrm{Ohm} \cdot \mathrm{cm}^{2}$, respectively. Obviously, the magnitude of the protective action obtained in the deaerated protective medium is $94.2 \%$ with SHFS and $~ 100 \%$ in the aerated medium (same surface coverage). Qualitatively, these figures reflect the real situation. In fact, as shown above, for calculations it is advisable to use reliable, constant in a wide range of potentials the Tafel slopes of the anodic and cathode sections of the potentiodynamic curves. This is possible if there are at least two conditions:

1. With increasing polarization, there is no change in the mechanism of electrode reactions.

2. It is permissible to neglect the ohmic component of the potential due to its magnitude, which is much smaller than the experimental error at significant polarization current densities.

Under conditions of formation of an air layer separating the solid and liquid phases, this condition is not satisfied, and the quantities $B_{\mathrm{c}}$ and $B_{\mathrm{a}}$ are variable and increase rapidly with increasing polarizing current density. In general, the protective effectiveness of superhydrophobic coatings in the corrosion of metals depends not only on their quality, which is determined, first of all, by the fraction of the surface area of the disturbed air layer, i.e. parts of the wetted surface, but also the ability of the liquid phase to displace the air gap, creating an L/S boundary. It is obvious that the kinetics of this process depends essentially on the time and nature of the phases present: metallic, liquid (corrosive medium) and superhydrophobic film.

In [6], the protective ability of the SHFS formed by the product used in [50] was studied in the conditions of corrosion of a magnesium alloy with additions of $\mathrm{Mn}$ and $\mathrm{Co}$ (MA8) in a $3 \% \mathrm{NaCl}$ solution. The hydrophobic layer $\theta=(131 \pm 2)^{\circ}$ was formed by the adsorption application of the product used earlier in [50] to a surface formed in turn by plasma electrochemical oxidation. To create SHFS, aerosil particles were applied to the hydrophobic layer $\theta_{\text {init }}=(166 \pm 3)^{\circ}$. The results of polarization measurements at such objects are given in Fig. 7.

Corresponding corrosion parameters of the alloy obtained in $3 \% \mathrm{NaCl}$ are summarized in Table 4.

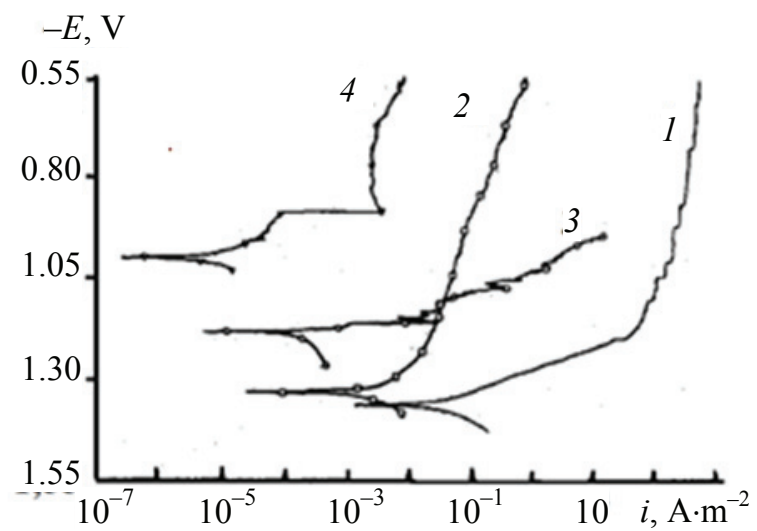

Fig. 7. Polarization curves taken in a $3 \% \mathrm{NaCl}$ solution for samples of the MA8 alloy.

Coating: 1 - no coating; 2 - plasma oxidation (PO); 3 - PO + hydrophobization; 4 - PO + superhydrophobization [6]

Table 4

The values of the potential, corrosion rate and polarization resistance observed on the MA8 alloy in a $3 \% \mathrm{NaCl}$ solution

\begin{tabular}{lccc}
\hline \multicolumn{1}{c}{ Coating } & $\begin{array}{c}-E_{\text {cor }}, \\
\mathrm{V}\end{array}$ & $\begin{array}{c}i_{\text {cor }}, \\
\mathrm{A} / \mathrm{m}^{2}\end{array}$ & $\begin{array}{c}R_{D}, \\
\mathrm{Ohm} \cdot \mathrm{cm}^{2}\end{array}$ \\
\hline No coating & 1,37 & $6,6 \cdot 10^{-2}$ & $7,2 \cdot 10^{2}$ \\
Plasma oxidation (PO) & 1,34 & $4,4 \cdot 10^{-3}$ & $6,2 \cdot 10^{4}$ \\
PO + hydrophobization & 1,19 & $1,6 \cdot 10^{-4}$ & $1,4 \cdot 10^{6}$ \\
PO + superhydrophobization & 1,01 & $1,5 \cdot 10^{-5}$ & $2,5 \cdot 10^{7}$ \\
\multicolumn{4}{c}{$\begin{array}{l}\text { N o te }: i_{\text {cor }} \text { were obtained by the method of impedance } \\
\text { spectroscopy using the Stern-Geary equation. }\end{array}$} \\
\hline
\end{tabular}




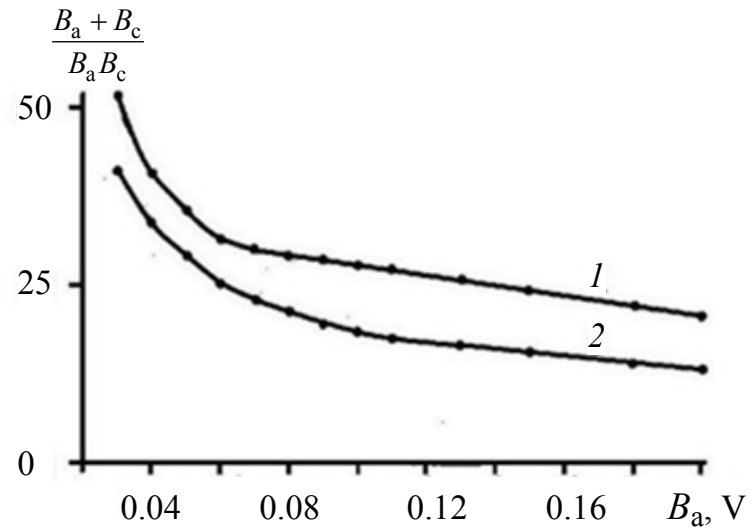

Fig. 8. Correlation between $\left(B_{\mathrm{a}}+B_{\mathrm{c}}\right) /\left(\boldsymbol{B}_{\mathrm{a}} \boldsymbol{B}_{\mathrm{c}}\right)$ and $\boldsymbol{B}_{\mathrm{a}}$ at constant value $B_{\mathrm{c}}$ :

$1-0.060 \mathrm{~V} ; 2-0.110 \mathrm{~V}$

The same approach using equation (3) was used by the authors [52]. Earlier it was noted that it is used quite widely. At the same time, as follows from curves 2 and $2^{\prime}$ in Fig. 6, there are no Tafel regions on both branches of the polarization curves. This is probably due to the fact that the portion of the wetted surface is very small, and the quality of the superhydrophobic film is very high. In this case, the values of $B_{\mathrm{a}}$ and $B_{\mathrm{c}}$, which are necessary for calculations using Eq. (3), cannot be estimated. The character of the polarization curves 2 and $2^{\prime}$ shown in Fig. 6, is due to the large contribution of the ohmic component to the measured electrode potential. Let us consider the accuracy of the estimates from Eq. (3).

Let the value $R_{D}=$ const. Then, according to (3), the value $i_{\text {cor }}$ is proportional to $\left(B_{\mathrm{a}}+B_{\mathrm{c}}\right) /\left(B_{\mathrm{a}} B_{\mathrm{c}}\right)$. Fig. 8 shows the relation $\left(B_{\mathrm{a}}+B_{\mathrm{c}}\right) /\left(B_{\mathrm{a}} B_{\mathrm{c}}\right)$ with $B_{\mathrm{a}}$ at constant values $B_{\mathrm{c}}$ equal to 0.060 и $0.110 \mathrm{~V}$. It is easy to understand that the value $i_{\text {cor }}$ should depend essentially on the value $B_{\mathrm{a}}$.

Thus, in this case, it is preferable to determine the value $i_{\text {cor }}$ by extrapolating the Tafel regions of the polarization curves to $E_{\text {cor }}$.

\section{Correlation between the surface superhydrophobization and conditions of its icing}

This issue was widely discussed due to its scientific and practical importance in a large number of studies [7-14]. Factors that prevent icing of surfaces were previously considered [13]. At the same time, there are works in which the correlation between the surface superhydrophobization and the difficulty of its icing was disputed [58-60]. Thus, according to [60], superhydrophobization of the surface does not reduce the adhesion of ice. In [13], the influence of a number of additional factors on the affinity of ice on a similar surface and its relation to the contact angle was estimated. Various methods have been used to create superhydrophobization, since the properties of ice models depend on the microphysical properties of the water droplets and weather conditions of their formation.

According to the data of [13], the energy of adhesion of ice is not the main hysteresis factor of the contact angle. The dominant effect is the level of roughness. On a very rough surface, the adhesion of ice during cycling is practically unchanged (shown on samples of type B [13]). At the same time, the level of surface roughness decreases with the growth of the cycle number.

The study was supported by the Russian Science Foundation, Project No. 18-16-00006.

\section{Acknowledgments}

The authors are sincerely grateful to Lyudmila Borisovna Boynovich, Lead Researcher of the Surface Forces Laboratory of the A.N. Frumkin Institute of Physical Chemistry and Electrochemistry, Academician of the Russian Academy of Sciences and to Alexander Mikhailovich Yemelyanenko, Head of this laboratory, Doctor of Physics and Mathematics, for systematic support and assistance in performing the experiment.

\section{References}

1. Boinovich L.B., Emelyanenko A.S. Gidrofobnye materialy i pokrytiya: printsipy sozdaniya, svojstva, primenenie [Hydrophobic materials and coatings: principles of creation, properties, application]. Uspekhi khimii [Advances in Chemistry]. 2008, vol. 77, issue 7, pp. 619-638 (Rus.)

2. Boinovich L., Emelyanenko A. A wetting experiment as a tool to study the physicochemical processes accompanying the contract of hydrophobic and superhydrophobic materials with aqueous media. Adv. Colloid Interface Sci. 2012, pp. 179-182.

3. Boinovich L., Emelyanenko A. Wetting and surface forces. Adv. Colloid Interface Sci. 2011, vol. 165, pp 60-69.

4. Boinovich L.B., Gnedenkov S.V., Alpysbaeva D.A., Egorkin V.S. Emelyanenko A.M., Sinebryukhov S.L., Zaretskaya A.K. Corrosion resistance of of composite coatings on low-carbon steel containing hydrophobic and superhydrophobic layers in combination with oxide sublayers. Corros. Sci. 2012, vol. 55, pp. 238-245.

5. Alpysbaeva D.A., Vershok D.B., Emel'yanenko A.M., Batishhev O.V., Kuznetsov YU.I., Bojnovich L.B. Supergidrofobizatsiya nizkouglerodistoj stali s konversionnymi pokrytiyami [Superhydrophobization of low-carbon steel with conversion coatings]. Korroziya: materialy, zashhita [Corrosion: materials, protection]. 2013, issue 8, pp. 42-47 (Rus.) 
6. Gnedenkov S.V., Egorkin V.S., Sinebryukhov S.P., Vyalyj I.E., Pashinin A.S., Emel'yanenko A.M., Bojnovich L.B. Supergidrofobnye kompozitnye pokrytiya na poverkhnosti magnievogo splava [Superhydrophobic composite coatings on the surface of magnesium alloy]. Vestnik DVO RAN. 2013, issue 5, pp. 3-11 (Rus.)

7. Wang Y., Xue J., Wang Q., Qingmin Chen Q., Ding J. Verification of icephobic/anti-icing properties of a superhydrophobic surface ACS. Appl. Mater. Interfaces 2013, vol. 5, pp. $3370-3381$

8. Momen G., Farzaneh M. Facile approach in the development of icephobic hierarchically textured coatings as corrosion barrier. Appl. Surf. Sci. 2014, vol. 299, pp. 41-46

9. Menini R., Ghalmi Z., Farzaneh M. Highly resistant icephobic coatings on aluminum alloys. Cold Reg. Sci. Technol. 2011, vol. 65, pp. 65-69.

10. Lazauskas A., Cuobiene A., Prosycevas I., Baltrusaitis V., Grigaliunas V., Narmontas P., Baltrusaitis J. Water, droplet behavior on superhydrophobic $\mathrm{SiO}_{2}$ nanocomposite films during icing/deicing cycles. Mater. Charact. 2013, vol. 82, pp. 9-16.

11. Zou M., Beckford S., Wei R., Ellis C., Hatton G., Miller M.A. Effects of surface roughness arid energy on ice adhesion strength. Appl. Surf. Sci. 2011, vol. 2, pp. 3786-3792.

12. Meuler A.J., Smith J.D., Varanasi K.K., Mabry J.M., McKinley G.H., Cohen R.E. Relationships between water wettability and ice adhesion ACS. Appl. Mater. Interfaces. 2010, vol. 2, pp. 3100-3110.

13. Momen G., Jafari R., Farzaneh M. Ice repellency behaviour of superhydrophobic surfaces: Effects of atmospheric icing conditions and surface roughness. Applied Surface Science. 2015, vol. 349, pp. 211-218.

14. Antonini C., Innocenti M., Horn T., Marengo M., Amirfazli A. Understanding the effect of superhydrophobic coatings on energy reduction in anti-icing systems. Cold Reg. Sci. Technol. 2011, vol. 67, pp. 58-67.

15. Bahadur V., Mishchenko L., Hatton B., Taylor J.A., Aizenberg J., Krupenkin T. Predictive model for ice formation on superhydrophobic surfaces. Langmuir. 2011, vol. 27, pp. 14143-14150.

16. Zhou Y., Niu S., Lu J. The influence of freezing drizzle on wire icing during freezing fog events. Advances in Atmospheric Sciences. 2013, vol. 30, pp. 1053-1069.

17. Meuler A.J., Smith J.D., Varanasi K.K. Mabry J.M., McKinley G.H., Cohen R.E. Relationships between water wettability and ice Adhesion. ACS. Appl. Mater. Interfaces. 2010, vol. 2, pp. 3100-3110.

18. Kulinich S.A., Farhadi S., Nose K., Du X.W. Superhydrophobic surfaces: Are they really ice-repellent? Langmuir. 2011, vol. 27, pp. 25-29.

19. Vigdorovich V.I., D'yachkova T.P., Pupkova O.D., Tsygankova L.E. Vzaimosvyaz' kinetiki vosstanovleniya ionov vodoroda na zheleze i potoka diffuzii $\mathrm{v}$ uglerodistuyu stal' $\mathrm{v}$ kislykh rastvorakh [The relationship between the kinetics of the reduction of hydrogen ions on iron and the diffusion flux into carbon steel in acidic solutions] Elektrokhimiya [Electrochemistry]. 2001, vol. 37, issue 12, pp. 1437-1445 (Rus.).

20. Sun T., Qing G., Biomimetic smart interface materials for biological applications. Adv. Mater. 2011, vol. 23, pp. 1157-1177.

21. Ko T.J., Kim E., Nagashima, Oh K.H., Lee K.R., Kim S., Moon M.W. Adhesion behavior of mouse liver cancer cells on nanostructured superhydropho-bic and superhydrophobic surfaces. Soft Matter. 2013, vol. 9, pp. 8705-8711.
22. Godolides E., Ellinas K., Tserepi A. Hierarchical micro and nano srtuctured, hydrophilic, superhydrophbic and superoleophobic surfaces incorporated in microfluidics, microarrays and lab on chip Microsystems. Microelectron. Eng. 2015, vol. 132, pp. 135-155.

23. Draper M.C., Crick C.R., Orlickaite V., Turek V.A., Parkin I.P., Edel J.B. Superhydrophobic surfaces as an on-chip microfluidic toolkit for total droplet control. Anal. Chem. 2013, vol 85, pp. 5405-5411.

24. Hua Z., Yang J., Wang T., Liu G., Zhang G. Transparent surface with reversibly switchable wettability between superhydrophobicity and superhydrophilicity. Langmuir. 2013, vol. 29, pp. 10307-10312.

25. Wang G., Zhang T.Y. Easy route to the wettability cycling of copper surface between syperhydrophobicity and superhydrophilicity. ACS Appl. Mater. Interfaces. 2012, vol. 4, pp. 273-279.

26. Chaundhary A., Barshilia H.C. Nanometric multiscale rough $\mathrm{CuO} / \mathrm{Cu}(\mathrm{OH})_{2}$ superhydrophobic surfaces prepared by a facile one-step solution-immersion process: transition to superhydrophilicity with oxygen plasma treatment. J. Phys. Chem. 2011, vol. 115, pp. 18213-18220.

27. Colson P., Schrijnemakers A., Vertruyen B., Henrist C., Cloots R. Nano-sphere lithography and hydrothermal grouth: how to increase the surface area and control revesible wetting properties of $\mathrm{ZnO}$ nanowire arrays? J. Mater. Chem. 2012, vol. 22, pp. 17086-17091.

28. Zhang M.-L., Jin F., Zheng M.-L., Liu J., Zhao Z.-S., Duan X.-M. High efficiency solar cell based on $\mathrm{ZnO}$ nanowire array prepared by different growth method. RSC Adv. 2014, vol. 4, pp. 10462-10467.

29. Kao T.-T., Chui Y.-Y. Fabrication and wetting characteristics of vertically self-aligned Zno nanorods formed by anodic aluminum axide template. J. Micro/Nanolithogr. MEMS MOEMS. 2014, vol. 13, p. 013003.

30. Huang B.-R., Lin J.-C. A facile synthesis of $\mathrm{ZnO}$ nanotubes ang their hydrogen sensing properties. Appl. Surf. Sci. 2013, vol. 280, pp. 945-949.

31. Pauporte T., Bataille G., Joulaud L.,Vermersch F.J. Well-aligned $\mathrm{ZnO}$ nanowire arrays prepared by seed-layer free electrodeposition and their Cassie-Wenzel transition after hydrophobization. J. Phys. Chem. 2009, vol. 114, pp. 194-202.

32. Elias J., Utke I., Yoon S., Bechelany M., Wiedenkaff A., Michler J., Philippe L. Electrochemical growth of $\mathrm{ZnO}$ nanowires on atomic layer deposition coated polystyrene sphere templates. Electrochim. Acta. 2013, vol. 110, pp. 387-392.

33. Patra S., Sarkar S., Bera S.K., Paul G.K., Ghoch R. Influence of surface topography and chemical structure on wettability of electrodeposited $\mathrm{ZnO}$ thin films. Appl. Phys. 2010, vol. 108, pp. 083507-083512.

34. Liu H., Feng L., Zhai J., Jiang L., Zhu D. Reversible wettability of a chemical vapor deposition prepared $\mathrm{ZnO}$ film between superhydrophobicity and superhydrophilicity. Langmuir. 2004, vol. 20, pp. 5659-5661.

35. Li H., Zheng M., Liu S., Ma L., Zhu C., Xiong Z. Reversible surface wettability transition between superhydrophobicity and superhydrophilicity on hierarchinal micro/nanostructure ZnO mash films. Surf. Coat. Technol. 2013, vol. 224, pp. 88-92.

36. Li Q., Chen Y., Luo L., Wang L., Yu Y., Zhai L. Photoluminescence and wettig behavior of $\mathrm{ZnO}$ nanopatticles/ nanorods array synthesized by thermal evaporation. J. Alloys Compd. 2013, vol. 560, pp. 156-160. 
37. Sun Z., Liao T., Liu K., Jiang L., Kim J.H., Dou S.X. Robist superhydrophobicity of hierarchical $\mathrm{ZnO}$ hollow microspheres fabricated by two-step self-assembly. Nano Research. 2013, vol. 6, pp. 726-735.

38. Liu Y., Lin Z., Lin W., Moon K.S., Wong C.P. Rewessible superhydrophobic-superhydrophilic transition of $\mathrm{ZnO}$ nanorod/epoxy composite films, ACS. Appl. Mater. Interfaces. 2012, vol. 4, pp. 3959-3964.

39. Jin C., Li J., Han S., Wang J., Sun Q. A durable, superhydrophobic, superoleophobic and corrosion-resistant coating with rose-like $\mathrm{ZnO}$ nanoflowers on a bamboo surface. Appl. Surf. Sci. 2014, vol. 320, pp. 322-327.

40. Gong M., Xu X., Yang Z., Liu Y., Lu H., Liu L. Structure, photoluminescence and wettability properties of well arrayed $\mathrm{ZnO}$ nanowires Grown by hydrothermal method. J. Nanosci. Nanotechnol. 2010, vol. 10, pp. 7762-7765.

41. Wang P., Zhang D., Qiu R., Wu J. Superhydrophobic metal-complex film fabricated electrochemically on copper as a barrier to corrosive medium. Corrosion Science. 2014, vol. 83, pp. 317-326.

42. Zhang B., Lu S., Xu W., Cheng Y. Controllable wettability and morpho-logy of electrodeposited surfaces on zinc substrates. Appl. Surf. Sci. 2016, vol. 360, pp. 904-914.

43. Vigdorovich V.I., Shel E.Yu., Tsygankova L.E., Shel N.V., Uryadnikov A.A. Vliyanie kontsentratsii ionov vodoroda na kinetiku partsial'nykh ehlektrodnykh reaktsij na stali s supergidrofobnoj poverkhnost'yu v kislykh khloridnykh sredakh [Influence of the concentration of hydrogen ions on the kinetics of partial electrode reactions on steel with a superhydrophobic surface in acidic chloride media] Korroziya: materialy, zashhita [Corrosion: materials, protection], 2017, no. 4 , pp.1-11.

44. Menini R., Ghalmi Z., Farzaneh M. Effect of different aluminum surface treatments on ice adhesion strength. Cold Reg. Sci. Technol. 2011, vol. 65, p. 65.

45. Bhushan B., Jung Y.C., Koch K. Self-cleaning efficiency of artificial superhydrophobic surfaces. Langmuir. 2009, vol. 25, pp. 3240-3248.

46. Zhang B., Lu S., Xu W., Cheng Y. Controllable wettability and morphology of electrodeposited surfaces of zinc substrates. Applied Surface Science 2016, vol. 360, pp. 904-914.

47. Vigdorovich V.I., Tsygankova L.E., Uryadnikov A.A., Knyazeva L.G., Tanygina E.D. Vliyanie nanokompozitnogo supergidrofobnogo pokrytiya na korroziyu i kinetiku ehlektrodnykh protsessov na stali v $0.5 \mathrm{M}$ rastvore $\mathrm{NaCl}$ [Effect of nanocomposite superhydrophobic coating on the corrosion and kinetics of electrode processes on steel in a $0.5 \mathrm{M} \mathrm{NaCl}$ solution]. Korroziya: materialy, zashhita [Corrosion: materials, protection], 2016, no. 7, pp. 12-18. (Rus.)

48. Vigdorovich V.I., Tsygankova L.E., Shel N.V., Knyazeva L.G., Uryadnikov A.A., Kuznetsova E.G. Kinetika i mekhanizm ehlektrodnykh reaktsij $\mathrm{v}$ pro-tsessakh korrozii metallov, $\mathrm{v}$ kislykh i nejtral'nykh khloridnykh rastvorakh [Kinetics and mechanism of electrode reactions in metal corrosion processes, in acidic and neutral chloride solutions] Korroziya: materialy, zashhita [Corrosion: materials, protection]. 2015, no. 4, pp. 22-30. (Rus.)

49. Qiu R., Zhang D., Wang P. Superhidrophobic-carbon fibre growth on a zinc surface for corrosion inhibition. Corrosion Science. 2013, vol. 66, pp. 350-359.

50. Khorsand S., Raessi K., Ashrafizaden F., Arenas M.A. Relationship between the structure and water repellency of nickel-cobalt alloy coating prepared by electrodeposition process. Surface Coatings Technology. 2015, vol. 376, pp. 296-304

51. Khorsand S., Raeissi K., Ashrafizadeh F., Arenas M.A., Conde A. Corrosion behavior of super-hydrophobic electrodeposited nickel-cobalt alloy film. Applied Surface Science. 2016, vol. 362, pp. 349-357.

52. Li J., Yang Y., Zha F., Lei Z. Facile fabrication of superhydrophobic $\mathrm{ZnO}$ Surfaces from high to low water adhesion. Mater. Lett. 2012, vol. 75, pp. 71-73.

53. Liu P., Cao I., Zhao W., Xia Y., Huang W. Li Z. Insights into the superhydrophobicity of metallic surfaces prepared by electrodeposition involving spontaneous adsorption of airborne hydrocarbons. Appl. Surf. Sci. 2015, vol. 324, pp. 576-583.

54. Hashemzadeh M., Raessi K., Ashrafizaden F., Khorsand S. Effect ammonium chloride on microstructure, superhydrophobicity and corrosion resistance of nickel coating. Surface Coating Technology. 2015, vol. 283, pp. 318-328.

55. Kulinich S.A., Farhadi S., Nose K., Du X.W. Superhydrophobic surfaces are they really ice-repellent. Langmuir 2011, vol. 27, pp. 25-29.

56. Jung S., Dorrestijn M., Raps D., Das A., Megaridis C.M., Poulikakos D. Are superhydrophobic surfaces best for icephobicity. Langmuir 2011, vol. 27, pp. 3059-3066.

57. Chen J., Liu J., He M., Li K., Cui D., Zhang Q., Zeng X., Zhang Y., Wang J., Song Y. Superhydrophobic surfaces cannot reduce ice adhesion. Appl. Phys. Lett. 2012, vol 101, pp. 111603-111613.

58. Sundin E., Makkonen L. Ice loads on a lattice tower estimated by weather station data. J. Appl. Meteorol. 1998, vol. 37, pp. 523-529.

59. Taylor P., Makkonen L. Ice adhesion - theory measurements and countermeasures. J. Adhes. Sci. Technol. 2012, vol. 26, pp. 37-41.

60. Kringlebotn Nygaard B.E., Kristjansson J.E., Makkonen L. Prediction of in-cloud icing conditions at ground level using the WRF model. J. Appl. Meteorol. 2011, vol. 50, pp. 2445-2459. 